\title{
Positive FP-CIT SPECT (DaTSCAN) in Clinical Alzheimer's Disease - An Unexpected Finding?
}

\author{
Verena Bittner ${ }^{\mathrm{a}}$ Gerhard Ullrich $^{\mathrm{b}}$ Markus Thormann $^{\mathrm{b}}$ \\ Notger G. Müller ${ }^{c}$ Christin Friederichs $^{b}$ Holger Amthauer $^{b}$ \\ Hans-Jochen Heinze ${ }^{a, c}$ Daniel M. Bittner ${ }^{a}$ \\ Departments of a Neurology, and ${ }^{b}$ Radiology and Nuclear Medicine, University of \\ Magdeburg, and ${ }^{\mathrm{C}}$ German Center of Neurodegenerative Diseases, Magdeburg, Germany
}

\section{Key Words}

Alzheimer's disease $\cdot$ Dementia $\cdot$ Dopamine $\cdot$ Lewy bodies $\cdot$ FP-CIT SPECT

\begin{abstract}
Clinically, Alzheimer's disease (AD) is by far the most common cause of dementia. Criteria for the diagnosis of dementia with Lewy bodies (DLB) are highly specific but not at all sensitive, which is reflected by the higher number of DLB cases detected histopathologically at autopsy. Imaging of dopamine transporter with FP-CIT SPECT is one possibility to increase sensitivity. Pathological confirmation was also included in the revised consensus criteria for the diagnosis of DLB. However, in the absence of parkinsonism, one of the core features, a clinical diagnosis of AD is more likely. The role of FP-CIT SPECT in DLB diagnosis remains to be clarified. Based on our 3 case reports and a review of the literature, the utility of this imaging method in the differential diagnosis of $A D$ and DLB is highlighted.

Copyright $\odot 2011$ S. Karger AG, Basel
\end{abstract}

\section{Introduction}

In postmortem studies, dementia with Lewy bodies (DLB) accounts for $10-20 \%$ of all cases of dementia and can therefore be regarded as the second most common cause of dementia after Alzheimer's disease (AD) [1-3]. For a definite diagnosis, autopsy is required. 
Table 1. Presence of core symptoms of DLB in the 3 cases

Dementia Parkinsonism Fluctuations Visual hallucinations

\begin{tabular}{lllll} 
Case 1 & + & - & + & - \\
Case 2 & + & - & - & + \\
Case 3 & + & - & $(+)$ & $(+)$ \\
\hline
\end{tabular}

Table 2. Basic demographic data for the 3 cases

\begin{tabular}{lccc}
\hline & Case 1 & Case 2 & Case 3 \\
\hline Age, years & 80 & 82 & 72 \\
Gender & male & male & male \\
Clinical symptom duration, years & 2 & 1 & 1 \\
MMSE & 28 & 24 & 26 \\
Phosphorylated tau, pg/ml & 107 & 62 & - \\
Tau, pg/ml & 404 & 408 & - \\
$\mathrm{A} \beta_{1-42}, \mathrm{pg} / \mathrm{ml}$ & 469 & 577 & - \\
\hline
\end{tabular}

However, confirmation of the diagnosis during the patient's lifetime is both reasonable and important, since patients with DLB respond to acetylcholine esterase inhibitors [4] and furthermore demonstrate a hypersensitivity to antipsychotic treatment $[5,6]$. Clinical consensus criteria from 1996 possess a fairly high specificity with $80-90 \%$ [7], but only a low sensitivity, decreasing to $30 \%$ according to some studies [8-10]. DLB is most commonly misdiagnosed as AD $[10,11]$. An improvement in clinical accuracy - particularly when AD is part of the differential diagnosis - seems to be worthwhile.

In postmortem studies, a $57-90 \%$ loss of presynaptic dopamine transporters could be demonstrated in $\mathrm{DLB}$ but not in $\mathrm{AD}[12,13]$. The presence a dopaminergic abnormality in DLB including striatal dopaminergic transporter loss was outlined in vivo with positron (PET) [14] and single-photon emission computed tomography (SPECT) [15, 16]. On the grounds of these observations, a positive, i.e. abnormal, FP-CIT-SPECT was included as a feature suggestive of DLB in the revised clinical consensus criteria from 2005 [17]. Sensitivity could thereby be increased up to $81.3 \%[18,19]$. Moreover, in a follow-up study over a period of 1 year, it was shown that in case of clinical suspicion, an FP-CIT scan may be helpful. Of 19 patients initially diagnosed as having possible and after 1 year as having probable DLB, 12 patients (63.2\%) had pathological FP-CIT-SPECT, while the remaining 7 cases that were assessed as non-DLB at the 1-year follow-up had normal DaTSCAN (100\% specificity) [19].

Another challenge in differential diagnosis resides in the distinction between Parkinson's disease and dementia (PDD). It is still an open question whether the underlying neurobiological changes result from one and the same mechanism in both entities. FP-CITSPECT is abnormal in both DLB and PDD [20, 21], possibly with a lower dopamine transporter uptake in PDD than in DLB [18]. Regarding the current clinical criteria, an agreement was reached that the diagnosis of DLB is not possible when extrapyramidal features are present for $>12$ months before the diagnosis of dementia [17]. In the following, we describe 3 cases who had no extrapyramidal signs, and thus DLB was the only possible diagnosis (table 1). Basic demographic data are listed in table 2. 


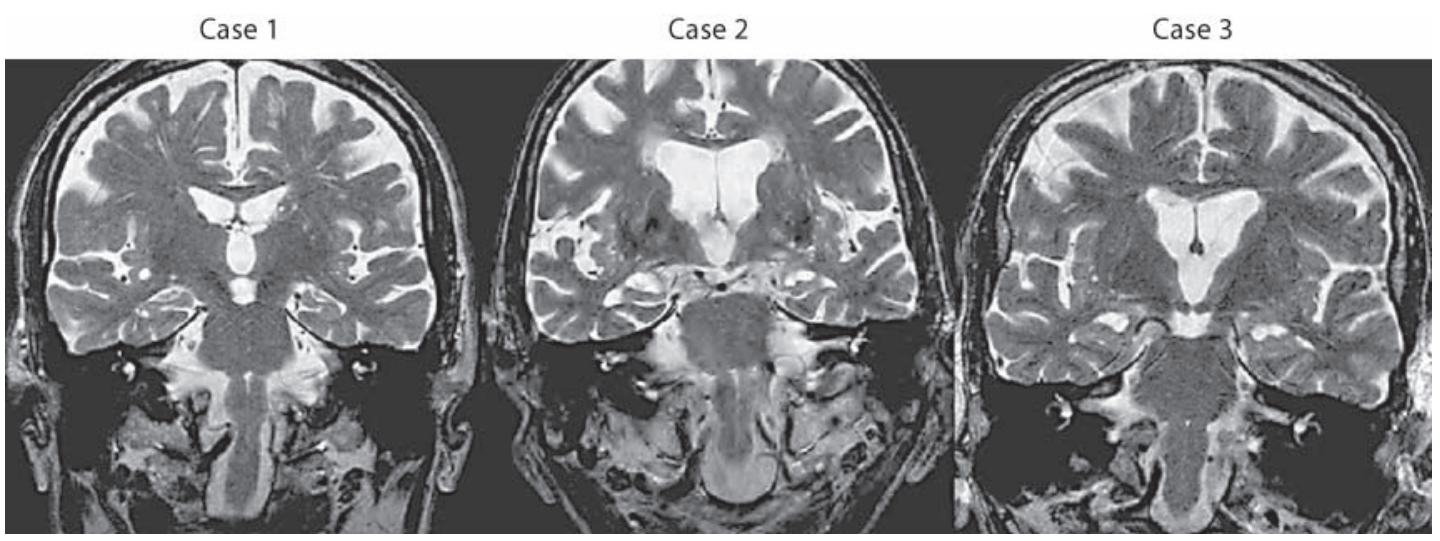

Fig. 1. cMRI of the 3 cases ( $\mathrm{T}_{2}$, coronal plane, including hippocampal area).

Table 3. Neuropsychological profiles of the 3 cases

\begin{tabular}{llll}
\hline & Case 1 & Case 2 & Case 3 \\
\hline MMSE & 28 & 24 & 26 \\
Attention & $\downarrow$ & $\downarrow$ & \\
Visuoconstruction & $\downarrow$ & $\downarrow$ & $\downarrow$ \\
Episodic memory & $\downarrow$ & $\downarrow$ & $\downarrow$ \\
Short-term/working memory & $\downarrow$ & $\downarrow$ & \\
Naming & $\downarrow$ & $\downarrow$ & $\leftrightarrow$ \\
Executive function & $\leftrightarrow$ & $\downarrow$ & $\downarrow$ \\
Orientation & $\leftrightarrow$ & $\leftrightarrow$ & $\leftrightarrow$ \\
\hline
\end{tabular}

$\downarrow=1.5$ SD below the median of a control sample (according to the respective test manuals); $\leftrightarrow$ = value within the normal range of controls.

\section{Case 1}

An 80-year-old male complained of progressively decreasing memory over the previous 2 years. Word finding was particularly difficult. Orientation in time and place was reduced, and he developed difficulties in finding the treatment rooms during hospitalization. Additionally, vision began to be disturbed. He scarcely read anymore due to the effort required. Financial affairs were managed together with his wife. Neurological examination was completely normal, and, in particular, there were no signs of rigidity, hypokinesia or tremor. The UPDRS-III motor score was 0 . Clinical chemistry did not reveal any significant abnormality apart from slightly elevated homocysteine $(16.1 \mu \mathrm{mol} / \mathrm{l})$. Mini Mental State Examination (MMSE) was within normal limits (28 of 30 points), but extensive neuropsychological testing revealed significant abnormalities regarding attention, visuospatial capabilities, short-term and working verbal memory, verbal episodic memory and naming. Orientation and executive functions were preserved (table 3). Moreover, during the session massive fluctuations were present. Cerebrospinal fluid (CSF) was normal with respect to basic parameters, but phosphorylated tau at threonine 231 was elevated and $\beta$-amyloid $\left(A \beta_{1-42}\right)$ was decreased. Cerebral magnetic resonance imaging (MRI) revealed no significant vascular lesions, but frontotemporal atrophy was noted, with relative preservation of hippocampal formation (fig. 1). 

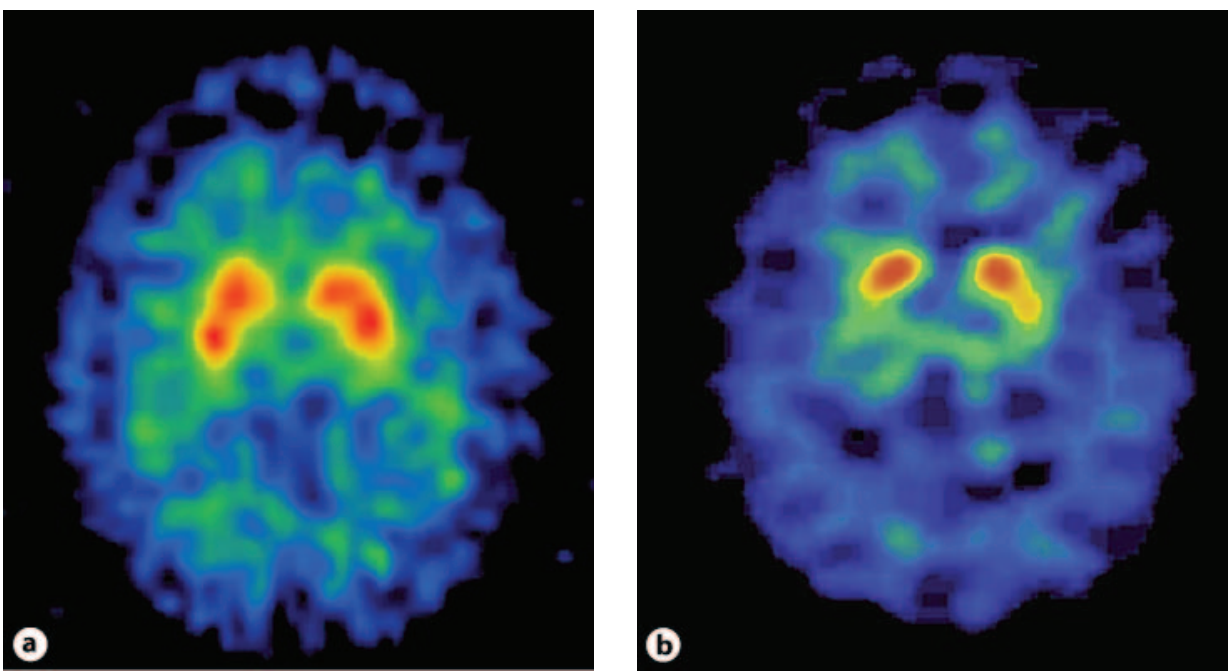

Fig. 2. a Heterogeneous decrease in striatal dopamine transporters, indirectly indicating the too high uptake of ${ }^{123}$ I-FP-CIT (DaTSCAN) in the background. b Decreased uptake of ${ }^{123}$ I-FP-CIT (DaTSCAN) in both putamina and normal uptake in both caudate nuclei. c Uptake of ${ }^{123} \mathrm{I}-\mathrm{FP}$ CIT (DaTSCAN) is almost absent in both putamina (accentuated on the left side) and normal in both caudate nuclei.

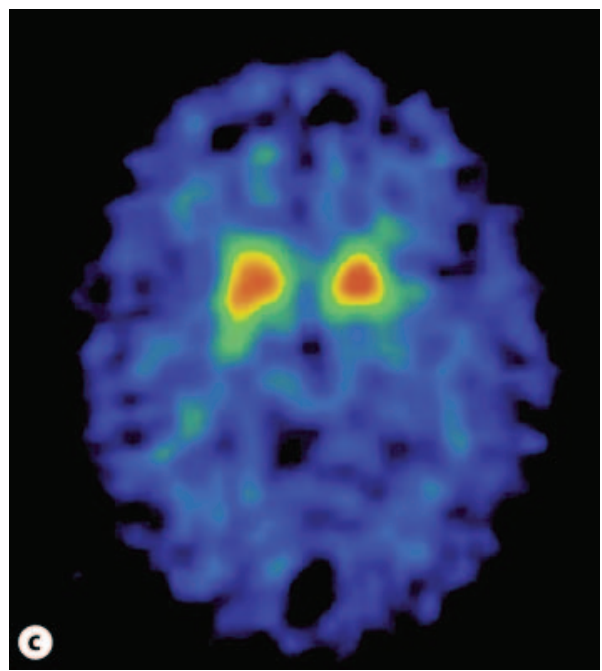

According to DSM IV [22] criteria, dementia was diagnosed and according to NINCDSADRDA criteria [23] probable dementia of the Alzheimer type was assumed: symptoms were progressive and were demonstrated in more than one cognitive domain. The findings were supported by typical CSF data. Although only one core feature (fluctuation) was present, FPCIT-SPECT was performed and revealed a diminished dopamine transporter uptake in the basal ganglia (fig. 2a). In conclusion, following the revised consensus criteria for DLB from 2005, probable DLB was diagnosed.

\section{Case 2}

An 82-year-old male with AD diagnosed 1 year previously was admitted to the inpatient neurological department due to uncontrolled visual hallucinations. On neurological examination, there were no abnormalities, particularly no extrapyramidal signs. UPDRS-III motor score was 0 . No fluctuations were observed or reported. In neuropsychology, MMSE was only slightly decreased ( 24 of 30 points), but apart from orientation all other cognitive do- 
mains were at least 1.5 SD from age-corrected means (attention, executive function, verbal short-term, working and episodic memory, naming and visuoconstruction; table 3). MRI of the head revealed global atrophy including the mesiotemporal region (fig. 1). CSF analysis was normal (including tau and $A \beta_{1-42}$ ). Due to the neuropsychological findings and at least one core feature of DLB, a DaTSCAN was performed and bilateral diminished dopamine transporter uptake was found (fig. 2b). On the basis of all the findings, a diagnosis of probable DLB was made.

\section{Case 3}

A 72-year-old male was admitted to the neurology outpatient clinic with subjective memory complaints. He had difficulty in remembering names and terms and moreover experienced spatial disorientation. Finally, completion of planned actions, e.g. handling of the coffee machine, were reported to be impaired. Neurological examination showed no abnormality, in particular no extrapyramidal signs. UPDRS-III motor score was 0. Only upon further inquiry, he admitted fluctuations and to some degree visual hallucinations although the latter more resembled misperception, were only of short duration and were not very well formed. Neuropsychologically, MMSE was almost within the normal range with 26 of 30 points, but deficits were found in visuospatial capabilities, executive function and verbal episodic memory, while orientation and naming were spared. Thorough assessment of attention was not performed (table 3). MRI of the head revealed some global atrophy but the mesiotemporal region, including the hippocampus, was spared (fig. 1). No CSF was obtained from this patient. DaTSCAN was performed and again dopamine transporter uptake was diminished (fig. 2c). A diagnosis of probable DLB was made.

\section{Discussion}

To be able to offer optimal therapeutic treatment, an accurate diagnosis during a patient's lifetime is important since DLB patients respond to therapy with acetylcholine esterase inhibitors $[6,24]$. In addition, in DLB patients the sensitivity to antipsychotics is increased, with a 2- to 3-fold increase in mortality [5]. Treatment with these drugs has to be rational and should be restricted to carefully selected substances. Although the clinical diagnosis offers a high specificity, sensitivity with respect to DLB is only very low, leading to an important role of supplemental imaging techniques. In particular, distinguishing DLB from $\mathrm{AD}$ and $\mathrm{PD}$ is important.

Differentiating between DLB and PDD does not require further investigation since they are distinguished by an anamnestic criterion: whether or not dementia has developed within 1 year of onset of extrapyramidal signs. Dementia onset during that period suggests a diagnosis of DLB, whereas a later onset of dementia is suggestive of PDD.

Differentiation between DLB and AD is less clear. Since there is a huge overlap of clinical criteria, distinction is not feasible in most cases. Additional diagnostic parameters are inappropriate. Results from biomarkers gained by lumbar puncture are very similar in both diseases. The increase in tau and phosphorylated tau and decrease in $A \beta_{1-42}$ sometimes found in $\mathrm{AD}$ is less pronounced in DLB $[25,26]$. However in a single case, distinction cannot be made. On MRI, mesiotemporal structures seem to be more affected in $\mathrm{AD}$, whereas in DLB mesencephalic regions are atrophied [27]. Again an evaluation of a single subject is very difficult. Another imaging technique, perfusion scintigraphy of the brain with ${ }^{99 \mathrm{~m}}$ Tc-bicisate (Neurolite), has been investigated for its possible role as a diagnostic tool. The patterns of 
hypoperfusion slightly deviate between DLB and AD, with more occipital involvement in $\mathrm{DLB}$, while in $\mathrm{AD}$ the characteristic finding is a temporoparietal hypoperfusion [28-36], but differences are not sufficient [37] or at least inferior to those found using FP-CIT-SPECT [38]. Hence depiction of the dopaminergic system using ligands such as FP-CIT offers the greatest potential for accurate diagnosis during a patient's lifetime. Neuroimaging is well tolerated by patients, particularly in early stages of the disease. Furthermore, SPECT is readily available, analysis is easily adapted to the diagnosis of DLB, and the procedure is not too time consuming. Reduction in FP-CIT is clearly and evidently associated with a fundamental neurobiological alteration recognized in DLB, namely dopaminergic loss $[12,13]$. The above-mentioned reasons explain the increased implementation of FP-CIT-SPECT in routine diagnostics to support a diagnosis of DLB.

The question of the utility of the FP-CIT-SPECT in the distinction between DLB and AD then arises, especially for an early diagnosis. In AD, extrapyramidal signs occur in $20-30 \%$, usually later in the course of the disease. Parkinsonism in early stages of dementia therefore argues against $\mathrm{AD}$ and favors $\mathrm{DLB}$. Thus, whether there are extrapyramidal signs or not has a substantial impact on the diagnosis made. Although parkinsonism is one of the core features of DLB and occurs frequently in the course of the disease, in up to $75-80 \%$ of cases [39, $40]$ it is not required for a probable diagnosis of DLB. In a review of histopathologically confirmed cases from a brain bank and the current literature, parkinsonism was only found as a first sign of DLB in about $50 \%$ of the 239 study patients [41, 42].

It remains to be clarified how often an FP-CIT-SPECT will be abnormal in the absence of parkinsonism, and what criteria should be met before a DaTSCAN is performed in case extrapyramidal signs are absent. Our 3 case reports indicate that a FP-CIT scan may indeed be abnormal in the absence of extrapyramidal signs. An overview of the current literature is difficult because in most of the cases there are no detailed clinical descriptions of the patients and their association with DaTSCAN findings. From the literature, an abnormal DaTSCAN was obtained in 6 of 7 cases when parkinsonism was absent $[18,43,44]$. Furthermore, an abnormal DaTSCAN was found in the presence of only minor motoric abnormalities in 7-8 of 11 patients (UPDRS < 15) in a further study [45]. In the light of these observations, it is interesting that even when extrapyramidal motor signs are present, an abnormal FP-CITSPECT is rarely found in $\mathrm{AD}[18,46]$, possibly pointing to an extrastriatal mechanism in the development of parkinsonism in $\mathrm{AD}$.

\section{Conclusion}

We conclude that to increase diagnostic accuracy FP-CIT-SPECT should be readily available once the criteria of possible DLB are met. As demonstrated in our cases, attention should be focused on neuropsychological findings, namely preserved orientation, fluctuating levels of attention and visuoconstructive deficits. The latter two have been shown to be sensitive to and predictive of DLB even in the early stages of mild cognitive impairment [47].

\section{Acknowledgment}

We gratefully acknowledge the assistance of Dr. Catherine Sweeney in correcting the English and her helpful discussions. 


\section{References}

1 McKeith IG, Burn DJ, Ballard CG, et al: Dementia with Lewy bodies. Semin Clin Neuropsychiatry 2003;8:46-57.

-2 Perry RH, Irving D, Blessed G, Fairbairn A, Perry EK: Senile dementia of Lewy body type: a clinically and neuropathologically distinct form of Lewy body dementia in the elderly. J Neurol Sci 1990; 95:119-139.

-3 Stevens T, Livingston G, Kitchen G, Manela M, Walker Z, Katona C: Islington study of dementia subtypes in the community. Br J Psychiatry 2002;180:270-276.

-4 McKeith I, Del Ser T, Spano P, et al: Efficacy of rivastigmine in dementia with Lewy bodies: a randomised, double-blind, placebo-controlled international study. Lancet 2000;356:2031-2036.

-5 Ballard C, Grace J, McKeith I, Holmes C: Neuroleptic sensitivity in dementia with Lewy bodies and Alzheimer's disease. Lancet 1998;351:1032-1033.

-6 McKeith I, Fairbairn A, Perry R, Thompson P, Perry E: Neuroleptic sensitivity in patients with senile dementia of Lewy body type. Br Med J 1992;305:673-678.

-7 McKeith IG, Galasko D, Kosaka K, et al: Consensus guidelines for the clinical and pathologic diagnosis of dementia with Lewy bodies (DLB): report of the Consortium on DLB International Workshop. Neurology 1996;47:1113-1124.

8 McKeith IG, O'Brien JT, Ballard C: Diagnosing dementia with Lewy bodies. Lancet 1999;354:12271228.

-9 Nelson PT, Jicha GA, Kryscio RJ, Abner EL, Schmitt FA, Cooper G, Xu LO, Smith CD, Markesberry WR: Low sensitivity in clinical diagnosis of dementia with Lewy bodies. J Neurol 2010;257:359-366.

-10 Lopez OL, Becker JT, Kaufer DI, et al: Research evaluation and prospective diagnosis of dementia with Lewy bodies. Arch Neurol 2002;59:43-46.

-11 McKeith IG, Ballard CG, Perry RH, et al: Prospective validation of consensus criteria for the diagnosis of dementia with Lewy bodies. Neurology 2000;54:1050-1058.

-12 Piggott MA, Marshall EF, Thomas N, et al: Striatal dopaminergic markers in dementia with Lewy bodies, Alzheimer's and Parkinson's diseases: rostrocaudal distribution. Brain 1999;122:1449-1468.

-13 Suzuki M, Desmond TJ, Albin RL, Frey KA: Striatal monoaminergic terminals in Lewy body and Alzheimer's dementias. Ann Neurol 2002;51:767-771.

14 Hu XS, Okamura N, Arai H, et al: ${ }^{18} \mathrm{~F}$-fluorodopa PET study of striatal dopamine uptake in the diagnosis of dementia with Lewy bodies. Neurology 2000;55:1575-1577.

-15 Donnemiller E, Heilmann J, Wenning GK, et al: Brain perfusion scintigraphy with ${ }^{99 \mathrm{~m}} \mathrm{Tc}-\mathrm{HMPAO}$ or ${ }^{99 \mathrm{~m}} \mathrm{Tc}-\mathrm{ECD}$ and ${ }^{123} \mathrm{I}-\beta$-CIT single-photon emission tomography in dementia of the Alzheimertype and diffuse Lewy body disease. Eur J Nucl Med 1997;24:320-325.

-16 Walker Z, Costa DC, Walker RW, et al: Differentiation of dementia with Lewy bodies from Alzheimer's disease using a dopaminergic presynaptic ligand. J Neurol Neurosurg Psychiatry 2002;73:134-140.

-17 McKeith IG, Dickson DW, Lowe J, Emre M, O’Brien JT, Feldman H, Cummings J, Duda JE, Lippa C, Perry EK, Aarsland D, Arai H, Ballard CG, Boeve B, Burn DJ, Costa D, Del Ser T, Dubois B, Galasko D, Gauthier S, Goetz CG, Gomez-Tortosa E, Halliday G, Hansen LA, Hardy J, Iwatsubo T, Kalaria RN, Kaufer D, Kenny RA, Korczyn A, Kosaka K, Lee VM, Lees A, Litvan I, Londos E, Lopez OL, Minoshima S, Mizuno Y, Molina JA, Mukaetova-Ladinska EB, Pasquier F, Perry RH, Schulz JB, Trojanowski JQ, Yamada M: Diagnosis and management of dementia with Lewy bodies: third report of the DLB Consortium. Neurology 2005;65:1863-1872.

-18 O’Brien JT, Colloby S, Fenwick J, Williams ED, Firbank M, Burn D, Aarsland D, McKeith IG: Dopamine transporter loss visualized with FP-CIT SPECT in the differential diagnosis of dementia with Lewy bodies. Arch Neurol 2004;61:919-925.

-19 O’Brien JT, McKeith IG, Walker Z, Tatsch K, Booij J, Darcourt J, Marquardt M, Reininger C, LBD Study Group: Diagnostic accuracy of ${ }^{123}$ I-FP-CIT SPECT in possible dementia with Lewy bodies. Br J Psychiatry 2009;194:34-39.

-20 Benamer TS, Patterson J, Grosset DG, et al: Accurate differentiation of parkinsonism and essential tremor using visual assessment of ${ }^{123}$ I-FP-CIT SPECT imaging: the $\left[{ }^{123} \mathrm{I}\right]$-FP-CIT Study Group. Mov Disord 2000;15:503-510.

-21 Booij J, Tissingh G, Boer GJ, et al: [23 I]FP-CIT SPECT shows a pronounced decline of striatal dopamine transporter labelling in early and advanced Parkinson's disease. J Neurol Neurosurg Psychiatry 1997;62:133-140. 
22 American Psychiatric Association: Diagnostic and Statistical Manual of Mental Disorders, ed 4, revised. Washington, American Psychiatric Association, 2000.

-23 McKhann G, Drachman D, Folstein M, Katzman R, Price D, Stadlan EM: Clinical diagnosis of Alzheimer's disease: report of the NINCDS-ADRDA Work Group under the auspices of Department of Health and Human Services Task Force on Alzheimer's Disease. Neurology 1984;34:939944.

-24 Samuel W, Caligiuri M, Galasko D, et al: Better cognitive and psychopathologic response to donepezil in patients prospectively diagnosed as dementia with Lewy bodies: a preliminary study. Int J Geriatr Psychiatry 2000;15:794-802.

-25 Gomez-Tortosa E, Gonzalo I, Fanjul S, Sainz MJ, Cantarero S, Cemillan C, Yebenes JG, del Ser T: Cerebrospinal fluid markers in dementia with Lewy bodies compared with Alzheimer's disease. Arch Neurol 2003;60:1218-1222.

-26 Vanderstichele H, De Vreese K, Blennow K, Andreasen N, Sindic C, Ivanoiu A, Hampel H, Bürger K, Parnetti L, Lanari A, Padovani A, DiLuca M, Bläser M, Olsson AO, Pottel H, Hulstaert F, Vanmechelen E: Analytical performance and clinical utility of the INNOTEST PHOSPHO-TAU181P assay for discrimination between Alzheimer's disease and dementia with Lewy bodies. Clin Chem Lab Med 2006;44:1472-1480.

-27 Whitwell JL, Weigand SD, Shiung MM, Boeve BF, Ferman TJ, Smith GE, Knopman DS, Petersen RC, Benarroch EE, Josephs KA, Jack CR Jr: Focal atrophy in dementia with Lewy bodies on MRI: a distinct pattern from Alzheimer's disease. Brain 2007;130:708-719.

-28 Albin RL, Minoshima S, D’Amato CJ, et al: Fluoro-deoxyglucose positron emission tomography in diffuse Lewy body disease. Neurology 1996;47:462-466.

-29 Ceravolo R, Volterrani D, Gambaccini G, et al: Dopaminergic degeneration and perfusional impairment in Lewy body dementia and Alzheimer's disease. Neurol Sci 2003;24:162-163.

-30 Gilman S, Koeppe R, Little R, et al: Differentiation of Alzheimer's disease from dementia with Lewy bodies utilising positron emission tomography with $\left({ }^{18} \mathrm{~F}\right)$ fluorodeoxyglucose and neuropsychological testing. Exp Neurol 2005;191(suppl 1):S95-S103.

-31 Higuchi M, Tashiro M, Arai H, et al: Glucose hypometabolism and neuropathological correlates in brains of dementia with Lewy bodies. Exp Neurol 2000;162:247-256.

-32 Ishii K, Imamura T, Sasaki M, et al: Regional cerebral glucose metabolism in dementia with Lewy bodies and Alzheimer's disease. Neurology 1998;51:125-130.

- 33 Ishii K, Yamaji S, Kitagaki H, et al: Regional cerebral blood flow difference between dementia with Lewy bodies and Alzheimer's disease. Neurology 1999;53:413-416.

-34 Minoshima S, Foster NL, Sima AA, et al: Alzheimer's disease versus dementia with Lewy bodies: cerebral metabolic distinction with autopsy confirmation. Ann Neurol 2001;50:358-365.

-35 Mirzaei S, Rodrigues M, Koehn H, et al: Metabolic impairment of brain metabolism in patients with Lewy body dementia. Eur J Neurol 2003;10:573-575.

- 36 Pasquier J, Michel BF, Brenot-Rossi I, et al: ${ }^{99 \mathrm{~m} T c-E C D-S P E C T ~ f o r ~ d i a g n o s i s ~ o f ~ d e m e n t i a ~ w i t h ~ L e w y ~}$ bodies. Eur J Nucl Med Mol Imaging 2002;29:1342-1348.

- 37 Varma AR, Talbot PR, Snowden JS, Lloyd JJ, Testa HJ, Neary D: A ${ }^{99 m} \mathrm{mc}-\mathrm{HMPAO}$ single-photon emission computed tomography study of Lewy body disease. J Neurol 1997;244:349-359.

-38 Lim SM, Katsifis A, Villemagne VL, Best R, Jones G, Saling M, Bradshaw J, Merory J, Woodward M, Hopwood M, Rowe CC: The ${ }^{18} \mathrm{~F}$-FDG PET cingulated island sign and comparison to ${ }^{123} \mathrm{I}-\beta$-CIT SPECT for diagnosis of dementia with Lewy bodies. J Nucl Med 2009;50:1638-1645.

- 39 Aarsland D, Ballard C, McKeith IG, Perry RH, Larsen JP: Comparison of extrapyramidal signs in dementia with Lewy bodies and Parkinson's disease. J Neuropsychiatry Clin Neurosci 2001;13:374379.

-40 Del Ser T, McKeith IG, Anand R, Cicin-Sain A, Ferrara R, Spiegel R: Dementia with Lewy bodies: findings from an international multicentre study. Int J Geriatr Psychiatry 2000;15:1034-1045.

41 Poewe W, Wenning GK: Atypical parkinsonism; in Brandt T, Caplan LR, Dichgans J, Diener HC, Kennard C (eds): Neurological Disorders: Course and Treatment. San Diego, Academic Press, 2003, pp 1081-1098.

-42 Geser F, Wenning G, Poewe W, McKeith IG: How to diagnose dementia with Lewy bodies: state of the art. Mov Disord 2005;20(suppl 12):S11-S20.

-43 Walker Z, Costa DC, Ince P, McKeith IG, Katona CLE: In-vivo demonstration of dopaminergic degeneration in dementia with Lewy bodies. Lancet 1999;354:646-647. 
44 Walker Z, Jaros E, Walker RWH, et al: Dementia with Lewy bodies: a comparison of clinical diagnosis, FP-CIT single photon emission computed tomography imaging and autopsy. J Neurol Neurosurg Psychiatry 2007;78:1176-1181.

-45 McKeith IG, O’Brien JT, Walker Z, Tatsch K, Booij J, Darcourt J, Padovani A, Giubbini R, Bonuccelli U, Volterrani D, Holmes C, Kemp P, Tabet N, Meyer I, Reininger C, DLB Study Group: Sensitivity and specificity of dopamine transporter imaging with ${ }^{123}$ I-FP-CIT-SPECT in dementia with Lewy bodies: a phase III, multicentre study. Lancet Neurol 2007;6:305-313.

-46 Ceravolo R, Volterrani D, Gambaccini G, Bernardini S, Rossi C, Logi C, Tognoni G, Manca G, Mariani G, Bonuccelli U, Murri L: Presynaptic nigro-striatal function in a group of Alzheimer's disease patients with parkinsonism: evidence from a dopamine transporter imaging study. J Neural Transm 2004;111:1065-1073.

-47 Molano J, Boeve B, Ferman T, Smith G, Parisi J, Dickson D, Knopman D, Graff-Radford N, Geda Y, Lucas J, Kantarci K, Shiung M, Jack C, Silber M, Pankratz VS, Petersen R: Mild cognitive impairment associated with limbic and neocortical Lewy body disease: a clinicopathological study. Brain 2010; 133(Pt 2):540-556. 